\title{
Percutaneous cryoablation of small pulmonary malignant tumors under computed tomographic guidance with local anesthesia for nonsurgical candidates
}

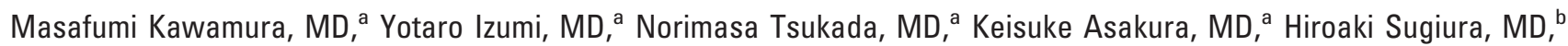
Hideki Yashiro, MD, ${ }^{\mathrm{b}}$ Keiko Nakano, MD, ${ }^{\mathrm{b}}$ Seishi Nakatsuka, MD, ${ }^{\mathrm{b}}$ Sachio Kuribayashi, MD, ${ }^{\mathrm{b}}$ and Koichi Kobayashi, MD

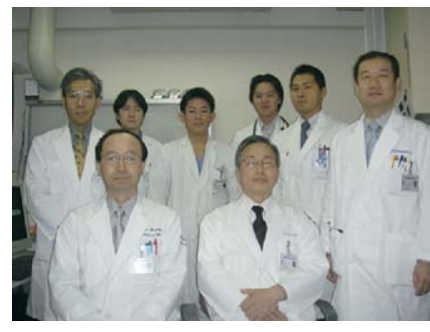

S. Kuribayashi, K. Kobayashi (in front),

S. Nakatsuka, H. Yashiro, Y. Izumi,

K. Asakura, N. Tsukada, M. Kawamura (in back), (left to right).
From the Divisions of General Thoracic Surgery $^{\mathrm{a}}$ and Diagnostic Radiology, ${ }^{\mathrm{b}}$ School of Medicine, Keio University, Tokyo, Japan.

Received for publication Oct 8, 2005; revisions received Dec 8, 2005; accepted for publication Dec 22, 2005.

Address for reprints: Masafumi Kawamura, MD, Division of General Thoracic Surgery, School of Medicine, Keio University, 35 Shinanomachi, Shinjuku-ku, Tokyo 160-8582, Japan (E-mail: kawamura@sc.itc.keio.ac.jp).

J Thorac Cardiovasc Surg 2006;131:1007-13 0022-5223/\$32.00

Copyright (๑) 2006 by The American Association for Thoracic Surgery

doi:10.1016/j.jtcvs.2005.12.051
Objective: Cryoablation of pulmonary metastases might be a useful therapy for nonsurgical candidates.

Methods: The procedure was performed after achievement of local anesthesia for 35 tumors in 20 patients ( 12 male and 8 female patients; mean age, 57 years). The primary end point was the safety and feasibility of cryoablation, and the secondary end point was tumor control assessed by follow-up dynamic computed tomographic scanning performed every 3 months.

Results: Of the 22 sessions of cryoablation, pneumothorax occurred in 11, hemoptysis occurred in 8 , and there was 1 case of phrenic nerve palsy. The mean hospital stay was 2.6 days. There was local recurrence of $7(20 \%)$ tumors in $7(35 \%)$ patients during a 9- to 28 -month (median, 21 months) follow-up period. One-year survival according to the Kaplan-Meier method was $89.4 \%$.

Conclusion: Percutaneous cryoablation therapy for metastatic lung tumors is feasible and minimally invasive, with satisfactory local control.

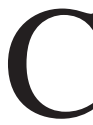
ryoablation is used to treat hepatocellular carcinoma ${ }^{1}$ or prostate carcinoma, ${ }^{2}$ but although Wang and associates ${ }^{3}$ have reported their experience of more than 200 cases of percutaneous pulmonary cryoablation during local anesthesia without major complications, the feasibility and efficacy of this technique for lung tumors have not been established.

Experiments in pigs have shown that a 2- or 3-mm-diameter cryoablation probe can freeze an area (known as an "ice ball") 2 to $3 \mathrm{~cm}$ in diameter and $4 \mathrm{~cm}$ in length after 2 cycles of freezing and thawing. ${ }^{4}$ Furthermore, a technique of puncturing the center of small intrapulmonary nodules under computed tomographic (CT) fluoroscopic guidance has been developed from the experience of CT-guided lung biopsy.

The surgical approach for small pulmonary metastases is usually a wedge (or incomplete) resection, which is considered sufficient for local curability. Good results after complete resection of isolated pulmonary metastases from extrathoracic malignancies have been reported, ${ }^{5}$ although others report that the extent of resection does not affect the prognosis. ${ }^{6}$ However, because patients with metastatic pulmonary tumors are likely to develop new lesions after treatment, the loss of pulmonary function associated with therapy should be minimal.

Therefore we considered that percutaneous cryoablation under CT guidance with local anesthesia as a locally curative treatment for small lung tumors $(<3 \mathrm{~cm}$ in diameter) should be possible and feasible. Our prospective study was approved by the institute's ethical review board. 


$$
\begin{aligned}
& \text { Abbreviations and Acronyms } \\
& \begin{aligned}
\text { CT } & =\text { computed tomography } \\
\text { PD } & =\text { progressive disease } \\
\text { PR } & =\text { partial response } \\
\text { RECIST } & =\text { Response Evaluation Criteria in Solid Tumors } \\
\text { RFA } & =\text { radiofrequency ablation } \\
\text { SD } & =\text { stable disease }
\end{aligned}
\end{aligned}
$$

\begin{tabular}{|c|c|c|}
\hline Age, y (mean [range]) & & $57(36-75)$ \\
\hline \multicolumn{3}{|l|}{ Sex $(n)$} \\
\hline Male & & $12(60 \%)$ \\
\hline Female & & $8(40 \%)$ \\
\hline \multicolumn{3}{|l|}{$\begin{array}{l}\text { Previous treatment for pulmonary } \\
\text { metastases }\end{array}$} \\
\hline Chemotherapy & & $8(40 \%)$ \\
\hline Radiotherapy & & $2(10 \%)$ \\
\hline Immunotherapy & & $1(5 \%)$ \\
\hline Pulmonary resection & & $4(20 \%)$ \\
\hline \multicolumn{3}{|l|}{ Main reason for no resection } \\
\hline Refusal of surgical intervention & & $6(30 \%)$ \\
\hline $\begin{array}{l}\text { Inadequate predicted } \\
\text { postoperative pulmonary } \\
\text { reserve }\end{array}$ & & $5(25 \%)$ \\
\hline Extrapulmonary metastases & & $8(40 \%)$ \\
\hline Asthma & & $1(5 \%)$ \\
\hline Primary cancer & Cases & Tumors \\
\hline Colorectal cancer & $6(30 \%)$ & $10(29 \%)$ \\
\hline Lung cancer & $5(25 \%)$ & $9(26 \%)$ \\
\hline Hepatic cancer & $2(10 \%)$ & $5(14 \%)$ \\
\hline Soft tissue sarcomas & $2(10 \%)$ & $4(11 \%)$ \\
\hline Head and neck cancer & $2(10 \%)$ & $3(9 \%)$ \\
\hline Uterus cancer & $2(10 \%)$ & $3(9 \%)$ \\
\hline Renal cancer & $1(5 \%)$ & $1(3 \%)$ \\
\hline \multicolumn{3}{|l|}{ No. of metastatic tumors } \\
\hline Solitary & & $11(55 \%)$ \\
\hline 2 & & $5(20 \%)$ \\
\hline 3 & & $2(10 \%)$ \\
\hline 4 & & $2(10 \%)$ \\
\hline \multicolumn{3}{|l|}{ Distribution of metastatic tumors } \\
\hline Unilateral & & $17(85 \%)$ \\
\hline Bilateral & & $3(15 \%)$ \\
\hline \multicolumn{3}{|l|}{ Tumor size } \\
\hline$\leq 10$ & & $13(37 \%)$ \\
\hline $11 \sim 20$ & & $17(49 \%)$ \\
\hline $21 \sim 30$ & & $5(14 \%)$ \\
\hline
\end{tabular}

TABLE 1. Characteristics of patients treated with cryoablation

\section{Methods \\ Patient Selection}

The study group comprised 20 consecutive patients with metastatic pulmonary tumors at Keio University Hospital from November 2002 through February 2004 selected according to the following criteria: (1) maximum tumor size less than $3 \mathrm{~cm}$ in diameter; (2) less than 5 metastatic tumors; (3) projected life expectancy of greater than 1 year; (4) absence of active extrapulmonary metastasis; (5) performance status of 0 to 1 on the Eastern Cooperative Oncology Group scale; (6) definite pathologic diagnosis of a metastatic tumor or obvious clinical features of pulmonary metastasis; (7) provision of written informed consent; and (8) normal coagulability.

The characteristics of the patients and the main reasons for the choice of cryoablation as an alternative to surgical resection are shown in Table 1.

\section{Cryoablation Technique}

Cryoablation was performed after achievement of local anesthesia by one thoracic surgeon and one radiologist. Before leaving the ward, each patient received an intramuscular injection of atropine sulfate $(0.5 \mathrm{mg})$ and pentazocine $(15 \mathrm{mg})$. In the CT room a 21-gauge guide needle was inserted into the center of the targeted tumors under fluoroscopic guidance, and when it was in the optimal position, a stainless-steel sheath for the cryoprobe, consisting of an inner guiding sheath and an external sheath, was inserted over the needle. The external sheath for a 2-mm-diameter cryoprobe (CRYOcare Cryosurgical Unit; Endo-care, Irvine, Calif) has inner and outer diameters of 2 and $3 \mathrm{~mm}$, respectively, and for a $3-\mathrm{mm}$ cryoprobe, these are $3 \mathrm{~mm}$ and $4 \mathrm{~mm}$, respectively. After the inner sheath was removed, either a 2- or 3-mm cryoprobe was inserted through the external sheath, which is $180 \mathrm{~mm}$ long, equivalent to the length of the cryoprobe, and therefore the cryoprobe tip was located at the end of the sheath (Figure 1). The cryoprobe uses high-pressure argon and helium gas for freezing and thawing, respectively, on the basis of the Joule-Thompson principle. Cryoablation consisted of 2 cycles of 5 minutes of freezing followed by thawing until the temperature of the cryoprobe increased to $20^{\circ} \mathrm{C}$ and then a third cycle of 10 minutes of freezing followed by thawing (Figure 2). The air in the lung can interfere with the creation of the ice ball. When the cryoprobe is inserted into normal pulmonary parenchyma, initial freezing can make an ice ball of 1 $\mathrm{cm}$ in diameter only because the air prevents conduction of low temperatures and there is not enough water in the parenchyma. However, after thawing, the massive intra-alveolar hemorrhage $^{4}$ excludes the air and results in a larger ice ball that forms in the following freezing. Therefore we performed 3 freezethaw cycles to make an ice ball of 2.5 to $3.0 \mathrm{~cm}$ in diameter. The 2- or 3-mm diameter cryoprobe can freeze an area of $2 \mathrm{~cm}$ and $3 \mathrm{~cm}$ in diameter, respectively, and $4 \mathrm{~cm}$ long after 3 cycles of freezing and thawing. Therefore for tumors smaller than $2 \mathrm{~cm}$, only 1 cryoprobe is usually inserted, and for $2-$ to $3-\mathrm{cm}$ tumors, 2 cryoprobes are used to secure a freezing margin.

After the cryoprobe is removed, fibrin glue is infused into the outer sheath, and when it coagulates, the outer sheath is removed while the inner sheath is used to push the coagulated fibrin into the track of the cryoprobe. This is done to reduce the risk of bleeding and pneumothorax.

It takes 20 to 30 minutes to place a guide needle into the optimal position in the targeted tumor, and cryoablation is not performed until all gauge needles are inserted. 


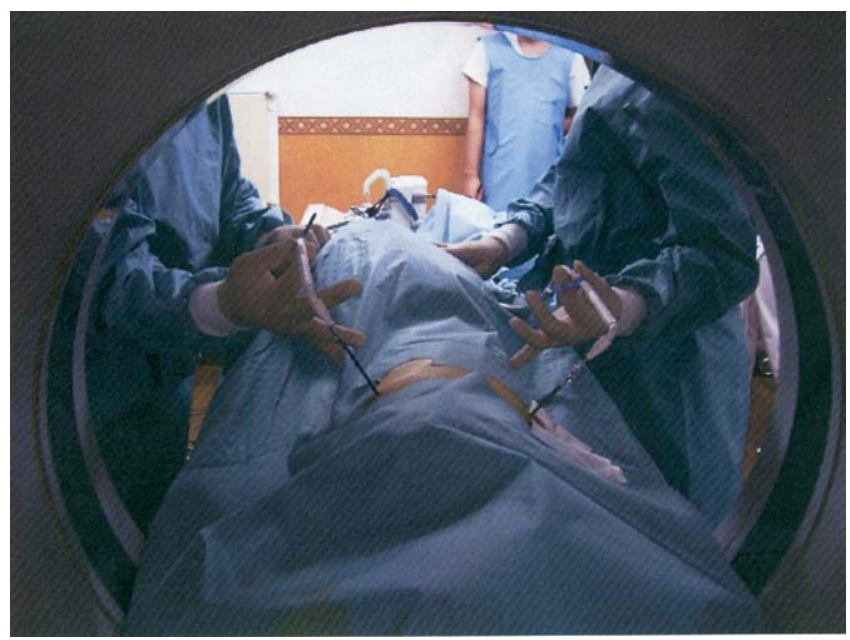

Figure 1. Two cryoprobes are inserted under computed tomographic (CT) guidance. CT scans can be taken as needed during the cryoablation procedure.

\section{Evaluation and Statistical Analysis}

The primary end point of this study was the early outcome and feasibility of using cryoablation for pulmonary metastatic tumors smaller than $3 \mathrm{~cm}$. The secondary end point was the effect of cryoablation on radiographically determined tumor control. We also evaluated the type and frequency of complications, radiographic evidence of tumor response after cryoablation treatment, and overall survival.

Patients underwent a preoperative chest CT scan and a repeat scan on the day after the cryoablation procedure. Follow-up dynamic CT chest scans of patients without iodine allergy were carried out at 1-month and then 3-month intervals. Increase of the treated lesion size on follow-up CT scan was diagnosed as local recurrence. In some cases CT-guided needle biopsy was added to obtain a definite diagnosis. Changes in tumor mass after cryoablation were measured according to the Response Evaluation Criteria in Solid Tumors (RECIST) protocol, ${ }^{7}$ which is based on objective measurements of lesion size before and after treatment. Complete response means lesion disappearance (scar) or less than $25 \%$ of original size. Partial response (PR) means a greater than $30 \%$ decrease in the sum of the largest diameter of all targeted lesions. Stable disease (SD) means a less than $30 \%$ decrease in the sum of the largest diameter of all targeted lesions. Progressive disease (PD) means an increase of greater than $20 \%$ in the sum of the largest diameter of all targeted lesions. Change in each tumor size is also important for evaluating the efficacy of cryoablation because patients with metastatic lung tumors usually have multiple metastatic lesions. Therefore change in each tumor was evaluated with the same protocol as RECIST. Because cryoablation can cause scar formation during the healing process, the lesion size after treatment alone does not necessarily reflect treatment efficacy. Therefore in addition to RECIST, clinical outcome according to the follow-up CT scan after more than 1 year can be noted.

The Kaplan-Meier method was used to analyze cumulative survival after the initial cryoablation.

\section{Results}

A total 35 pulmonary tumors in 20 patients (12 male and 8 female patients; mean age, 57 years; age range, 36-75 years) were treated with cryoablation. Eastern Cooperative Oncology Group performance status was 0 in 19 patients and 1 in 1 patient. In all cases cryoablation was performed percutaneously under CT guidance with local anesthesia without any major complications. None of the patients had major complications associated with the procedure. The pulmonary metastases were from colorectal cancer $(n=6)$, previously resected non-small cell lung cancer $(n=5)$, head and neck cancer $(\mathrm{n}=2)$, soft tissue sarcoma $(\mathrm{n}=2)$, hepatic cancer $(n=2)$, uterine cancer $(n=2)$, and renal cancer $(\mathrm{n}=1)$. The number of metastases was 1 in 11 patients, 2 in 5 patients, 3 in 2 patients, and 4 in 2 patients; 3 patients had bilateral metastases, and of them, 2 underwent cryoablation twice with an interval of 1 to 2 months, and the other patient underwent simultaneous cryoablation for the metastases. Therefore a total of 22 sessions of cryoablation were performed. The size of the treated lesions was 6 to $10 \mathrm{~mm}$ in 13 tumors, 11 to $20 \mathrm{~mm}$ in 17 tumors, and 21 to $30 \mathrm{~mm}$ in 5 tumors (mean tumor size, $13.3 \mathrm{~mm}$ ).

The main reasons why those patients underwent cryoablation instead of surgical intervention were refusal of surgical intervention in 6 patients, inadequate predicted postoperative pulmonary reserve in 5 patients, extrapulmonary metastases in 8 patients, and asthma in 1 patient (Table 1).

Pneumothorax occurred in 11 of the 22 sessions, primarily after the completion of the ablation procedure. A chest tube was inserted in 1 case, transient needle aspiration was performed in 3 cases, and in 7 cases no additional treatment was given. In 7 cases a small amount of pleural effusion was detected on a chest CT scan carried out on postoperative day 1 , but no additional treatment was required. Pleural dissemination was detected during the follow-up period in 1 patient whose postoperative CT scans did not show any pleural effusion. Because there had been multiple pulmonary metastases on the lung surface, it is unclear whether the cryoablation induced pleural dissemination. Hemoptysis occurred during 8 sessions and subsided in a few days in all patients. There was no apparent correlation between tumor location and the incidence of hemoptysis. Phrenic nerve palsy occurred during 1 session for a tumor located near the left phrenic nerve and had not improved when the patient died of brain metastases 9 months later (Table 2).

Mean hospital stay after treatment was 2.6 days (range, 2-9 days), although for the initial 5 sessions, it was 5.4 days. There were no treatment-related deaths or conversion to surgical intervention.

The response to cryoablation according to RECIST was complete response in 2 patients, $\mathrm{PR}$ in 8 patients, SD in 8 patients, and $\mathrm{PD}$ in 2 patients, giving a response rate of $50 \%$. In 3 of 8 patients with PR and 2 of 8 patients with SD, 
(1)

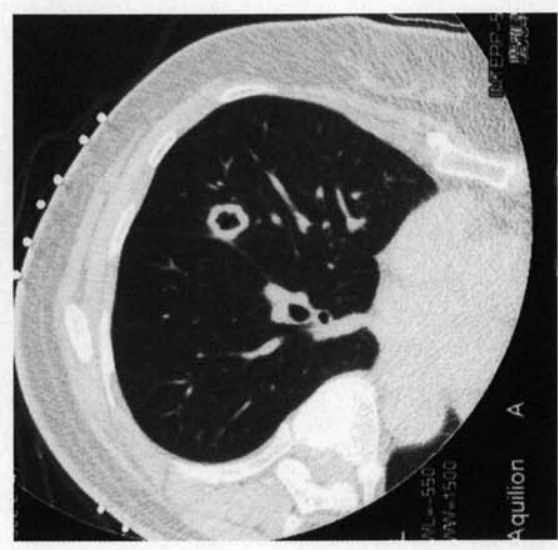

(4)

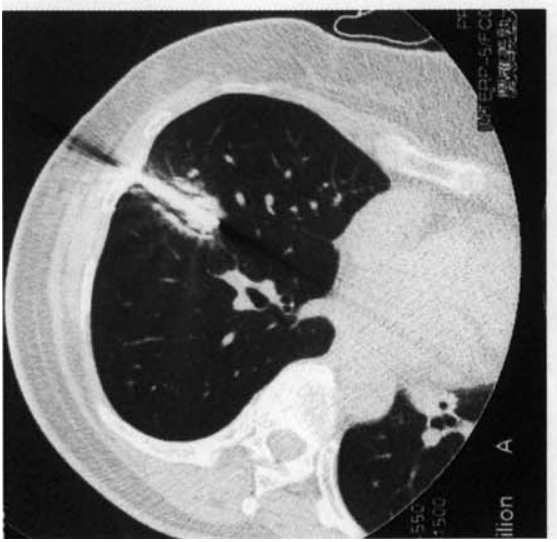

(2)

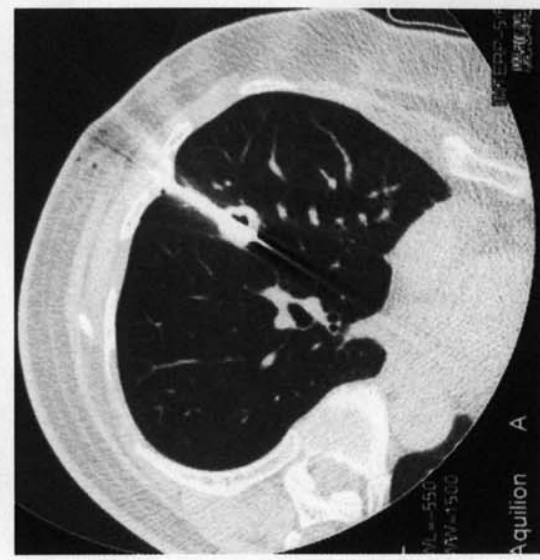

(5)

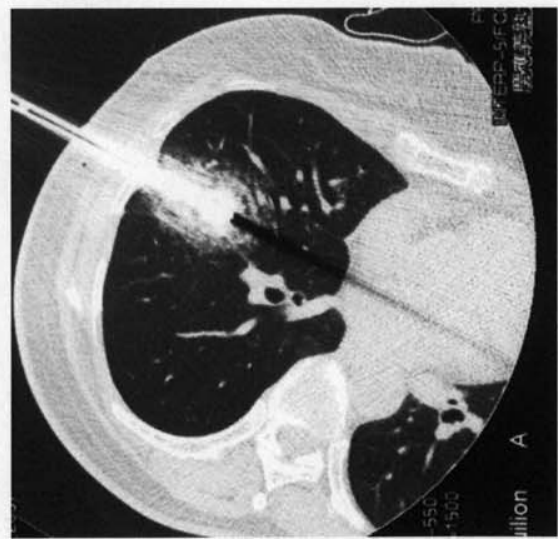

(3)

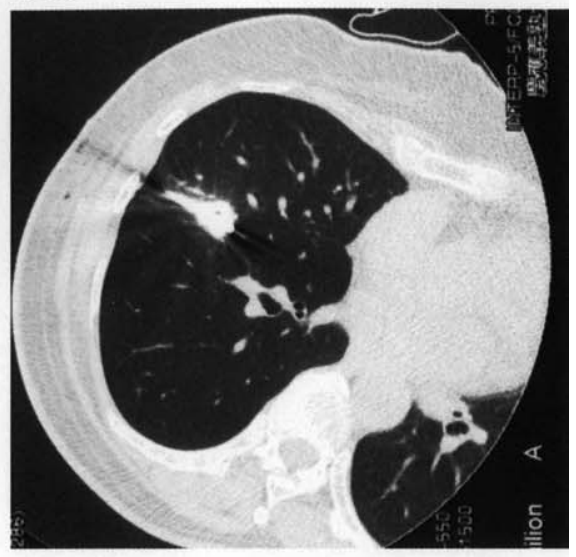

(6)

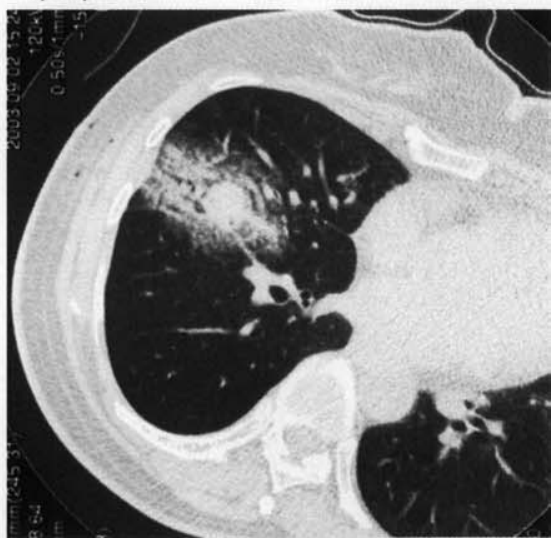

Figure 2. Sequential changes of the pulmonary parenchyma on computed tomographic scanning after freezing and thawing. 1, The metastatic tumor is located in right S4. 2, The cryoprobe penetrates the tumor. 3, Five minutes after the beginning of first freezing, the change of surrounding lung is quite small. 4, After first thawing, consolidation along the cryoprobe can be seen. 5, Five minutes after the beginning of second freezing, extension of the consolidated area can be seen. 6, After third thawing.

there was tumor recurrence. The response of each tumor was complete in 8 patients, partial in 11 patients, SD in 14 patients, and $\mathrm{PD}$ in 2 patients, giving a response rate of $54.3 \%$.

One patient died of brain metastases 9 months after cryoablation, and another patient died of bone and kidney metastases 10 months later, but neither had pulmonary local recurrence. The remaining 18 patients survived more than 1 year. The follow-up period was 9 to 28 months (median, 21 months), and in the 9 to 12 months after cryoablation, there was local recurrence of $7(20 \%)$ tumors (median time to progression of 9 months) in 7 (35\%) patients: 5 patients underwent repeat cryoablation without complications, 1 patients initially refused surgical intervention and underwent surgical resection, and 1 patients was given chemotherapy for both the recurrent and new lesions. There was 1 case of suspected subcutaneous recurrence along the insertion track, which was surgically resected. To date, there have been no cases of local recurrence after repeat cryoablation (Table 3).

\section{TABLE 2. Complications after cryoablation}

\begin{tabular}{lcc}
\hline Complication & No. & $\%$ \\
\hline Pneumothorax & 11 & 50 \\
Chest tube & 1 & 4.5 \\
Manual aspiration & 3 & 13.5 \\
Course observation & 7 & 32 \\
Pleural effusion & 6 & 27 \\
Hemosputum & 9 & 41 \\
Phrenic nerve palsy & 1 & 4.5 \\
Chest wall implantation & 1 & 4.5 \\
\hline
\end{tabular}


TABLE 3. Radiographic response and clinical result

\begin{tabular}{|c|c|c|c|c|c|}
\hline Patient no. & Primary tumor & $\begin{array}{l}\text { Nodules treated } \\
\text { with cryoablation }\end{array}$ & RECIST & $\begin{array}{l}\text { Each tumor's } \\
\text { response }\end{array}$ & $\begin{array}{c}\text { Clinical outcome (prognosis after initial } \\
\text { cryoablation) }\end{array}$ \\
\hline 1 & Synovial sarcoma & 1 & CR & CR & $\begin{array}{l}\text { New pulmonary lesions (18 POM } \\
\text { dead) }\end{array}$ \\
\hline 2 & NSCLC & 2 & $\mathrm{PR}$ & $\mathrm{PR}, \mathrm{SD}$ & Disease free (27 POM alive) \\
\hline 3 & NSCLC & 1 & $\mathrm{PR} \rightarrow \mathrm{PD}$ & $\mathrm{PR} \rightarrow \mathrm{PD}$ & $\begin{array}{l}\text { Recryoablation for local recurrence } \\
\text { (26 POM alive with new } \\
\text { pulmonary lesions) }\end{array}$ \\
\hline 4 & Colon cancer & 1 & SD & SD & $\begin{array}{l}\text { New pulmonary lesions (25 POM } \\
\text { alive) }\end{array}$ \\
\hline 5 & Head and neck cancer & 1 & SD & SD & $\begin{array}{l}\text { New pulmonary lesions (24 POM } \\
\text { alive) }\end{array}$ \\
\hline 6 & Colon cancer & 1 & PD & PD & $\begin{array}{l}\text { Recryoablation for local recurrence } \\
\text { (18 POM alive with new } \\
\text { pulmonary lesions) }\end{array}$ \\
\hline 7 & Colon cancer & 4 & $\mathrm{SD} \rightarrow \mathrm{PD}$ & $\mathrm{PR}, \mathrm{SD}, \mathrm{SD}, \mathrm{SD} \rightarrow \mathrm{PD}$ & $\begin{array}{l}\text { Surgical resection for local } \\
\text { recurrence ( } 21 \text { POM disease free) }\end{array}$ \\
\hline 8 & Lung cancer & 1 & $\mathrm{PR} \rightarrow \mathrm{PD}$ & $\mathrm{PR} \rightarrow \mathrm{PD}$ & $\begin{array}{l}\text { Recryoablation for local recurrence } \\
\text { (21 POM disease free) }\end{array}$ \\
\hline 9 & Colon cancer & 1 & SD & SD & $\begin{array}{l}\text { Surgical resection for subcutaneous } \\
\text { implantation (21 POM alive with } \\
\text { new pulmonary lesions) }\end{array}$ \\
\hline 10 & Hepatic cancer & 4 & PR & PR, SD, SD, CR & $\begin{array}{l}\text { New metastatic lesions (19 POM } \\
\text { alive) }\end{array}$ \\
\hline 11 & NSCLC & 2 & PR & PR, PR & Brain metastasis (9 POM dead) \\
\hline 12 & Head and neck & 2 & $\mathrm{SD} \rightarrow \mathrm{PD}$ & $\mathrm{CR}, \mathrm{SD} \rightarrow \mathrm{PD}$ & $\begin{array}{l}\text { Recryoablation for local recurrence } \\
\text { (18 POM disease free) }\end{array}$ \\
\hline 13 & NSCLC & 3 & $\mathrm{PR} \rightarrow \mathrm{PD}$ & $\mathrm{CR}, \mathrm{PR}, \mathrm{SD} \rightarrow \mathrm{PD}$ & $\begin{array}{l}\text { Chemotherapy for local recurrence } \\
\text { and new lesions (18 POM alive) }\end{array}$ \\
\hline 14 & Neurofibrosarcoma & 3 & CR & CR, CR, CR & $\begin{array}{l}\text { New metastatic lesions (18 POM } \\
\text { alive) }\end{array}$ \\
\hline 15 & Hepatic cancer & 1 & SD & SD & Disease free (16 POM alive) \\
\hline 16 & Colon cancer & 2 & PR & CR, PR & $\begin{array}{l}\text { Bone and kidney metastases } \\
\text { (10 POM dead) }\end{array}$ \\
\hline 17 & Renal cancer & 1 & PR & PR & Disease free (14 POM alive) \\
\hline 18 & Uterus cancer & 1 & PD & PD & $\begin{array}{l}\text { Recryoablation for local recurrence } \\
\text { (14 POM disease free) }\end{array}$ \\
\hline 19 & Colon cancer & 1 & SD & SD & $\begin{array}{l}\text { New metastatic lesions (14 POM } \\
\text { alive) }\end{array}$ \\
\hline 20 & Uterine cancer & 2 & SD & $\mathrm{PR}, \mathrm{SD}$ & Disease free (12 POM alive) \\
\hline
\end{tabular}

RECIST, Response Evaluation Criteria in Solid Tumors; CR, complete response; POM, post operative months; NSCLC, non-small cell lung cancer; $P R$, partial response; $S D$, stable disease; $P D$, progressive disease.

The 1-year survival rate after the initial cryoablation therapy for metastatic pulmonary tumors was $89.4 \%$, as determined by using the Kaplan-Meier method (Figure 3).

\section{Discussion}

Surgical intervention is the usual option for local cure of metastatic pulmonary cancer, and wedge resection, which preserves residual pulmonary function better than radical lobectomy with mediastinal lymph node dissection, results in local curability to some extent. According to the International Registry of Lung Metastases, ${ }^{5}$ the 5-year survival rate after incomplete resection for a metastatic lung tumor is $13 \%$ and $36 \%$ after complete resection, which suggests that surgical treatment might contribute to survival. However, some patients with advanced cancer might not tolerate surgical resection. Hence if equally effective, a less invasive therapy is preferable. This is why we evaluated the local curability, as well as the feasibility, of cryoablation. Although cryoablation has been performed for hepatic ${ }^{1}$ or prostate ${ }^{2}$ cancer and achieved acceptable results, in most cases it has been performed after achievement of general or epidural anesthesia. In our clinical study all the procedures 


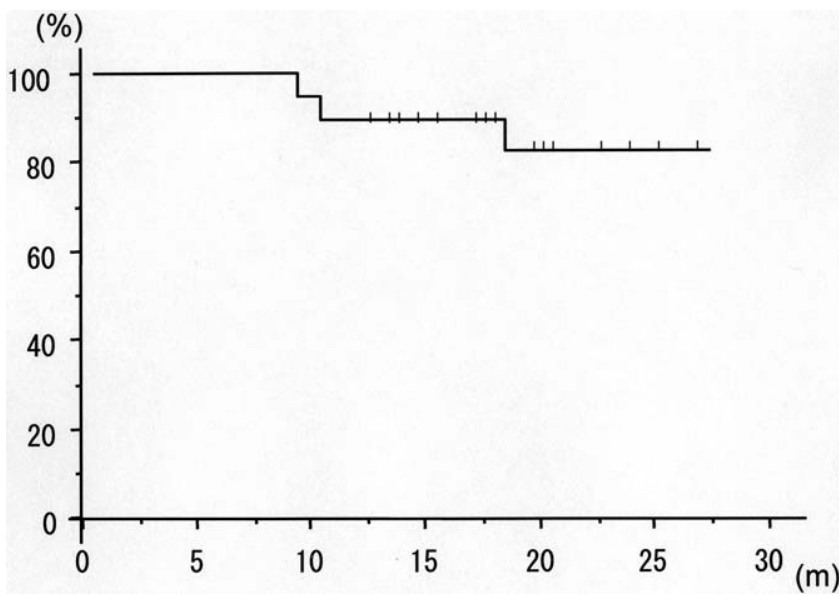

Figure 3. Accumulated survival curve by means of the KaplanMeier method.

were performed after administration of local anesthesia only, which is similar to the conditions in the study by Wang and colleagues. ${ }^{3}$ Moorjani and associates ${ }^{8}$ reported the effect of cryoanalgesia on the intercostal nerves, and from the viewpoint of treatment-associated pain, cryoablation seems an ideal technique. However, some patients complained of dull pain in the anterior chest after treatment, which we suspect was related to freezing of the intercostal nerves, and it usually disappeared within a few months.

One patient required a chest tube for pneumothorax, but for the other 10 cases of a small amount of air leakage, transient manual aspiration was sufficient to control it. Hemothorax requiring chest tube drainage did not occur. Izumi and coworkers 9 observed from animal experiments that the coagulated blood surrounding the outer sheath apparently prevents massive air leakage and bleeding in the damaged pulmonary tract. The patient with the chest tube remained in the hospital for 9 days after treatment, but the average hospital stay was 2.6 days, which is shorter than the 4.5 days after video-assisted wedge resection at the same hospital.

As for other complications, hemoptysis occurred in 50\% of sessions. In animal experiments rupture of the capillary wall and hemorrhage in the alveolar space were observed microscopically in the frozen area after thawing. ${ }^{4}$ We suppose this phenomenon is a kind of hemorrhagic pulmonary edema caused by the death of endothelial cells. Therefore hemoptysis seems inevitable after pulmonary cryoablation and is not a serious condition because it is caused by the rupture of capillaries rather than large vessels. Actually, hemoptysis was not usually associated with shortness of breath.

There are some reports on the use of radiofrequency ablation (RFA) for pulmonary malignancies. ${ }^{10-13}$ The RFA devices are more compact and cheaper than those for cryoa-

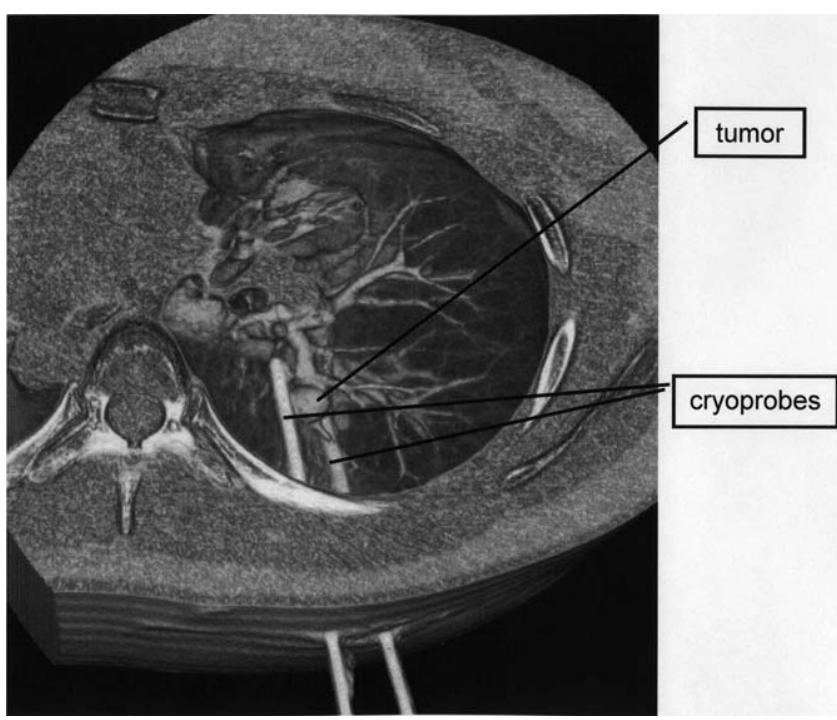

Figure 4. Cryoprobe can approach to the hilar lesions. A case with 6 peripheral and 1 central metastases: 6 peripheral metastases had been resected surgically. A centrally located tumor is shown in a 3-dimensional computed tomographic image. Two cryoprobes are inserted into the lung. Because the tumor was located close to a large vessel, 2 probes are inserted almost parallel, like chopsticks, so as to encase the tumor. This avoids vessel and airway damage, and preserves pulmonary function.

blation. It was reported that in RFA 1 retreated patient with metastatic disease died of massive hemoptysis 21 days after open RFA of a central nodule. ${ }^{10}$ Because the patient had also undergone brachytherapy 4 days prior, the cause of the fistula between the bronchus and the large pulmonary vessel was unclear; however, the authors state that they have ceased using RFA for central nodules since that complication.

We used cryoablation for centrally located tumors in 3 cases without any major complications (Figure 4), although the number of patients in this study is small. We know that the bronchial wall can resist temperatures of $-120^{\circ} \mathrm{C}$ to $-130^{\circ} \mathrm{C}$ because tracheas obtained from cadavers for transplantation can be deep-frozen. ${ }^{14,15}$ Some reports suggest that the collagenous architecture of the central bronchi and vasculature is preserved by endobronchial cryotherapy. ${ }^{16-18}$ On the other hand, the wall of large blood vessels heated by circulating blood during cryoablation seems to preserve the vessel wall structure.

Because metastatic lung tumors are expected to potentially associate with the other latent metastatic lesions in the lung, pulmonary reserve after treatment seems important. When cryoablation can be applied to centrally located tumors, greater pulmonary reserve is expected after cryoablation than after a surgical procedure such as lobectomy, which is usually required for the resection of those tumors (Figure 4). 
For tumors larger than $2.0 \mathrm{~cm}$ in diameter, 2 or more cryoprobes are usually inserted around the tumor, but in those cases, the ice ball is irregular in shape, and it is difficult to accurately assess the positional relationship of the tumor and ice ball on CT images, although 3-dimensional CT should help. However, more basic research is required, and we do not use cryoablation for tumors larger than $3.0 \mathrm{~cm}$ in diameter. Nevertheless, there was local recurrence of approximately $20 \%$ of the ablated tumors and further improvements in the technique, and the CT images are necessary to decrease this rate. Of course, another cause of local recurrence after cryoablation is that the metastatic tumor might have satellite lesions or there is microinvasion into the lymph ducts, and local treatment, such as cryoablation or wedge resection, has the limitation to curative local control of metastatic lung tumors.

The response of the tumors was evaluated according to RECIST, and even though the marked scar formation around the tumor after cryoablation would seem to make accurate evaluation of tumor size on CT images impossible, of the 11 of 14 tumors diagnosed as SD by RECIST, local recurrence has not occurred during follow-up of more than 14 months. Long-term follow-up with CT scanning periodically is thought to be the most appropriate way to evaluate local control of tumors after cryoablation. Positron emission tomography might also be very useful to evaluate local control, although we have not done this in the present study. Because all cases of recurrence occurred 6 to 12 months (median, 9 months) after cryoablation, particular attention must be given to this period, especially for the common metastatic lung tumors, although longer observation of low-grade malignant tumor is necessary. A larger multi-institutional study would be ideal to further evaluate feasibility, but we need to collect more data before such studies can be designed. We also need to train individuals to gain better recognition of this technique. At our institution, we start by training the techniques necessary for CT-guided biopsy.

\section{Conclusion}

Percutaneous cryoablation therapy for metastatic lung tumors was feasible and minimally invasive, with satisfactory local control. This technique could also be used without any serious complications for tumors located near the hilar pulmonary vessels. However, the number of patients enrolled in this study was small, and thus the efficacy of cryoablation for the treatment of metastatic lung cancer is still unclear. A larger phase II study comparing cryoablation with wedge resection, stereotactic radiotherapy, or RFA therapy is necessary to determine its efficacy and role in the local control of metastatic lung tumors. Overall, we consider that with further studies and more accurate estimation of the ablated volume, eventually in selected cases cryoablation might not be inferior to wedge resection for the local control of metastatic lung tumors.

\section{References}

1. Seifert JK, Junginger T. Cryotherapy for liver tumors: current status, perspectives, clinical results, and review of literature. Technol Cancer Res Treat. 2004;3:151-63.

2. Bahn DK, Lee F, Badalament R, Kumar A, Greski J, Chemick M. Targeted cryoablation of the prostate: 7-year outcomes in the primary treatment of prostate cancer. Urology. 2002;60(suppl):3-11.

3. Wang H, Littrup PJ, Duan Y, Zhang Y, Feng H, Nie Z. Thoracic mass treated with percutaneous cryotherapy: initial experience with more than 200 procedures. Radiology. 2005;235:289-98.

4. Izumi Y, Oyama T, Ikeda E, Kawamura M, Kobayashi K. The acute effects of transthoracic cryoablation on normal lung evaluated in a porcine model. Ann Thorac Surg. 2005;79:318-22.

5. Dastorino U, Buyse M, Friedel G, Ginsberg RJ, Girard P, Goldstraw P, et al. Long term results of lung metastasectomy: prognostic analyses based on 5206 cases: the International Registry of Lung Metastases. J Thorac Cardiovasc Surg. 1997;113:37-49.

6. Sakamoto T, Tsubota N, Iwanaga K, Yuki T, Matsuoka H, Yoshimura M. Pulmonary resection for metastases from colorectal cancer. Chest. 2001;119:1069-72.

7. Tsuchida Y, Therasse P. Response evaluation criteria in solid tumors (RECIST): new guidelines. Med Pediatr Oncol. 2001;37:1-3.

8. Moorjani N, Zhoo F, Tian Y, Liang C, Kaluba J, Maiwand MO. Effects of cryoanalgesia on post-thoracotomy pain and on the structure of intercostals nerves: a human prospective randomized trial and histological study. Eur J Cardiothorac Surg. 2001;20:502-7.

9. Izumi Y, Oyama T, Kawamura M, Kobayashi K. Lung biopsy with a 12 gauge cutting needle is possible using an insertion sheath in animal model. Acad Radiol. 2004;11:1278-81.

10. Herrera LJ, Fermando HC, Perry Y, Gooding WE, Buenaventure PO, Christie NA, et al. Radiofrequency ablation of pulmonary malignant tumors in nonsurgical candidates. J Thorac Cardiovasc Surg. 2003; 125:929-37.

11. Yasui K, Kanazawa S, Sano Y, Fujiwara T, Kagawa S, Miura H, et al. Thoracic tumors treated with CT-guided radiofrequency ablation: initial experience. Radiology. 2004;231:850-7.

12. Dupuy DE, Zagoria RJ, Akerley W, Mayo-Smith WW, Kavanaugh PV, Safran H. Percutaneous radiofrequency ablation of malignancies in the lung. Am J Roentgenol. 2000;174:57-9.

13. Sewell PE, Jackson MD, Vance RB, Wang YD. Assessing radiofrequency ablation of non-small cell lung cancer with positron emission tomography (PET) [abstract]. Radiology. 2000;217:551.

14. Yokomise $\mathrm{H}$, Inui $\mathrm{K}$, Wada $\mathrm{H}$, Hasegawa $\mathrm{S}$, Ohno $\mathrm{N}$, Hitomi $\mathrm{S}$. Reliable cryopreservation of trachea for one month in a new trehalose solution. J Thorac Cardiovasc Surg. 1995;110:382-5.

15. Yokomise H, Inui K, Wada H, Ueda M, Hitomi S. Reliable long-term cryopreservation of trachea for tissue banks. Transplant Proc. 1996; 28:1119-20.

16. Maiwand MO. The role of cryosurgery in palliation of tracheo-bronchial carcinoma. Eur J Cardiothorac Surg. 1999;15:764-8.

17. Deygas N, Froudarakis M, Ozenne G, Verguon JM. Cryotherapy in early superficial bronchogenic carcinoma. Chest. 2001;120:26-31.

18. Iomasson JP. Bronchoscopic cryotherapy. J Bronchol. 1995;2:145-53. 